\title{
Abstracciones ilustradas. A propósito del pragmatismo de Richard Rorty
}

\author{
MANUEL GARCÍA SERRANO \\ Universidad de Oviedo
}

\section{Reatismo metafisico}

1. En los reactualizados debates filosóficos en torno a los problemas del realismo, en el frente antirrealista se agrupa un variopinto elenco de posiciones. El realismo contra el que este frente arremete puede adoptar a su vez configuraciones diversas según cada posición. Pero la configuración más controvertida está próxima a lo que Kant denominó realismo trascendental y $\mathrm{H}$. Putnam ha llamado realismo metafísico. ${ }^{1}$ Un realista de ese jaez se figura que la realidad en su conjunto, o ciertas entidades paradigmáticamente reales, están reguladamente constituidas antes de la puesta en marcha de toda empresa cognitiva, ardua o sencilla. Las pretensiones de validez que ornan a los frutos de esas empresas se reconocerían o denegarían en atención a su buen o mal acuerdo con ese regulado orden antecedente. Propiamente el síntoma que permite diagnosticar la afección metafísica de un realista es la índole que adopta su empeño en delimitar, para apreciar ese acuerdo, un espacio eminente de realidad allende del que ocupan tales empresas, con el cual éstas habrfan de ser confrontadas. Los hechos son una de csas confrontadoras eminencias substanciales que tales realistas esgrimen en sus duelos ontológicos. Mas el solo saludable apego empirista a los hechos no hace de un realista un realista metafísico. Ese rasgo específico únicamente se adquiere cuando se obra bajo la suposición adicional de que cabe concebir lo que es un hecho haciendo abstracción de lo que es un enunciado verdadero. Una alternativa que se les abre a los realistas metafísicos cuando advierten la dificultad de determinar hechos prescindiendo de los enunciados a los que esos hechos verifican, es substraer a los hechos, en beneficio de otras entidades, su ejemplar carácter mundano: el mundo no sería entances el conjunto de los hechos, sino de las cosas o eventos. ${ }^{2}$

Ahora bien, si concebimos como cosas o eventos algo que es posible objeto de identificación, ni cosas ni eventos gozan de una eminencia substancial más señalada que los hechos. Siendo asi que una identificación efectiva de un objeto da cumplimiento a la intención de identificar a ese objeto, y dado que esa intención es precisamente la de que ese objeto sea identificado, se han puesto ahí en marcha recursos descriptivos, cuando menos tácitos, que determinan que la identificacion misma sea fiel tributaria de un lenguaje completo. Se comprende, entonces, que cada identificación de un objeto presente no sea sino un nuevo episodio añadido a la larga historia de nuestros encuentros con objctos, en una ruta temporal ordenada por relaciones de continuidad y conexión narrativamente. En esta narración, ligada a la autoconciencia de cada sujeto, se enmadejan conexiones entre unos y otros objetos, en forma tal que es una condición de la narración misma que el sujeto 
que recuerda o advierte sus encuentros con objetos no pueda ser un objeto como cualquier otro. Su peculiaridad como objeto es la de ser un objeto provisto de estados intencionales; un objeto que realiza enunciados.

Un tipo moderno de realista metafísico ha intentado, sin embargo, atenuar esta intervención lingüistica del sujeto apelando a una relación causal especial: aquella relación causal que guardan los objetos con el sujeto cuando impulsan a ćste a emitir ciertas secuencias de enunciados empíricos más bien que otras. El caso relevante es el de aquellas situaciones en las que ciertos objetos son, «en razón de ciertas circunstancias", condición necesaria para el uso oportuno de términos refe. renciales, o en que ciertas ocurrencias de objetos lo son para la formulación de enunciados verdaderos, o para la concepción de creencias acertadas o de intenciones realizables. Es el caso en que si tales objetos no hubieran estado dados, o tales hechos no hubieran sido efectivos —en virtud, por ejemplo, de una manipulación $o$ intervención humana-, no se habría identificado lo que se identificó, o no se habria afirmado el enunciado verdadero que se afirmó, o emprendido la acción que se emprendio. ${ }^{3}$ En rigor, todo tipo de realista ha de dar por asentada esta relación de causalidad. Lo que confiere ahora el especifico rasgo metafísico a un realista es la suposición de que esta relación está constituida como tal al margen de la autoconciencia del sujeto y de la puesta en marcha de un lenguaje; el sujeto mismo, y sus hábitos linguísticos, estaría incluido por entero como una parte más en un sistema causal general. Una primcra dificultad en que se enreda esta suposición la genera nuestra propia noción de causa, que se halla notoriamente ligada a nociones como explicación y curso. Una relación causal ha de tener un curso -entre esto y eso, con el efecto de eso o aquello-, un curso causal ha de ser en algo explicativo y nada es explicativo al margen de un lenguaje y de unos sujetos. Una explicación es siempre pertinente a expectativas perfiladas por un marco discursivo. La eminente cadena causal entre objetos y sujetos, o entre, por ejemplo, objetos y términos referenciales usados por esos sujetos, no puede incorporar por cormpleto a los sujetos y a su lenguaje dentro de la cadena causal.

La segunda dificultad de esa suposición del realista metafísico es más sirnple: la confianza que tenemos en que existen en absoluto ordenados cursos causales, y no meras secuencias temporales aleatorias, es de una naturaleza especial: es un imperativo dictado por nuestras experiencias de que algo es percibido como algo real, y no ilusorio, y de que nuestras acciones planificadas, en tanto generadoras de efectos que son causas de otros efectos, han sido exitosas, y no malogradas. La familiar estructura causal que asociamos a la marcha de las cosas no es un rasgo más de nuestro mundo que descubrimos en el mundo. No es propiamente algo que descubrimos. Es, primero, un presupuesto de nuestra contraposición entre percepciones fieles, causadas por el correspondiente objeto percibido, y percepciones ilusivas, cuyas causas no tienen por contenido el contenido de la propia percepcion. Y es, segundo, un presupuesto de nuestra contraposición entre intenciones de acción realizables - por razón de la eficacia de las causas activadase intenciones de acción irrealizables - por razón de la ausencia de medios causales para los fines perseguidos. No sucede que al contemplar el mundo e intervenir en su marcha hallamos un general sistema causal, sino que como 
observadores y actores estamos comprometidos a suponer ese sistema causal en virtud de lo que constitutivamente es contemplar el mundo e intervenir en su marcha.

La naturaleza de la brecha que el realista metafísico abre entre mundo $y$ sujeto, o mundo y lenguaje, le hace proclive también a recelar de la variopinta proliferación de entes reales que es contraparte de las pretensiones objetivas de las diversas empresas cognitivas que acometen los hombres. Para una subclase de los realistas metafísi$\cos$, solo hay un mundo primordial y sólo cierto tipo de eminentes entes reales; paralelamente, sólo habria sitio para una fiel versión descriptiva del mundo. La dificultad de este punto de vista reside ahora en que no tiene medio de discriminar las versiones descriptivas infieles comparándolas con ese mundo único, porque no cabe acceder al mundo dejando a un lado los bártulos de sus descripciones. El realista monista no puede apelar a un tribunal de estados indescritos, o a un ojo inocente, $y$ ha de conformarse con blandir. su tipo preferido de versión frente a las restantes. $Y$ así es como fácilmente se ve envuelto en lances quijotescos contra molinos de viento psicologicos, históricos, artísticos, morales... $\mathrm{O}$ al frente de vanas acometidas unificadoras contra la dispersa multiplicidad de composiciones y descomposiciones de clases de objetos, de criterios de relevancia y trivialidad entre estados de cosas, de elementos primitivos y de ordenaciones, de suplementos a lo inmediatamente dado u omisiones de ello... 4

\section{Pragmatismo}

1. Los filosofos, ahora bien, que encuentran objecioncs de peso que oponer al realismo metafísico componen, como dijimos, una larga cadena de posiciones, a lo largo de la cual son ofrecidas como alternativas a ese realismo distintas formas de idealismo y de realismo de otros cuños, y donde el acento de la cuestion va recayendo sobre distintas crestas tcmáticas. Una de esas crestas es el problema del significado, otra el problema de la verdad, una tercera el problema mente-cuerpo, una cuarta el problema de los juicios morales... Dentro de la cadena, un eslabón particularmente provocativo, $y$ que acoge a un tiempo varios de estos acentos, se distancia del marco kantiano de doctrina que es punto clásico de apoyo para la mayoria de las arremetidas contra el realismo metafísico. En ese eslabón está enclavada la obra de Richard Rorty. Como es sabido, Rorty guarda especiales reservas hacia ciertos rasgos de época que marcan a la filosofía kantiana y la convierten en un episodio de la Ilustración: esos rasgos se hacen, en particular, patentes en el afecto por un género de abstracciones característicamente enfatizadas por el optimismo ilustrado.5 Algunas de esas abstracciones presiden aún, sin duda, la cosmovisión predominante en las sociedades modernas: así lo hacen, por ejemplo, a través de las invocaciones a la Razón, concebida como una facultad humana que mantiene con las realizaciones $y$ habilidades racionales individuales una relación de abstracción análoga a la que media entre la competencia lingüística $y$ las individuales habilidades retóricas o realizaciones literarias. En estrecha unión con esta familiar abstracción de la moderna idea de Razón está configurada la idea de una naturaleza esencial del yo. Este yo esencial comprendería, por una parte, un esquema conceptual básico, en gracia al cual nos sería dado disputar sobre un marco de racionalidad común el valor de verdad de cada tipo de pro- 
posición empirica, o el mérito y demérito de cada teoría. Y por detrás de los abigarrados intereses individuales y del ilimitado surtido de cosas deseables creado al compás del tiempo, ese yo comprendería, por otra parte, un elenco de intereses nucleares comunes, luego a su vez a la base de abstracciones morales tales como los uderechos humanos». Aun con color más desvaído, una última señalada abstracción ilustrada persiste entre nosotros unida a la confianza - ya no exenta de desazones- en el progreso cognitivo. Bajo esa confianza, no se acepta la sola extensión social momentánea de una creencia como garantía suficiente de su acierto, así como tampoco se acepta la implantación posterior de la creencia opuesta como garantía suficiente de lo contrario. Suponemos que, más allá de la sólida impregnancia de una nueva creencia, lo que da sentido a la representación de un progreso cognitivo es que esa nueva creencia se acabe ajustando a la terca realidad de las cosas (y en la sazón de que se trate de una nueva convicción moral, también a una norma justa). Por más que el tribunal de los hechos no abra sus sesiones antes de que los sujetos cubran trámites lingǘsticos, ya cubiertos estos, a tal tribunal se le presume un grado de independencia.

En el propio seno del pensamiento moderno, estas y otras abstracciones afines han sido una fuente de problemas filosóficos de caudal constante. Lo incitante de la posición de Rorty y de otros autores agrupados bajo el vago epigrage de "postmodernismo" es que eluden tales problemas por el drástico método de desecar su fuente: ni el Tribunal de los hechos, ni un Yo de mayestática personalidad universal, ni los Principios morales, por ejemplo, serian abstracciones bienaventuradas y lo recomendable sería librar al mundo de tal familia de entelequias. ${ }^{6}$ El antikantismo deflacionista no está dirigido contra los rasgos generales del «idealismo trascendental" kantiano, que son propiamente compartidos por todos los críticos del realismo metafísico. Si se dirige, en cambio, contra cjertos rasgos específicos de ese idealismo, contra el realismo empirico que Kant profesó adicionalmente y contra su universalismo ético. La articulación intencional que el sujeto da a sus experiencias, o su creativismo conceptual o energía abductiva, o la secularización moral del sujeto moderno no son, así pues, el foco del conflicto. Este foco se concentra en los tres puntos dichos: 1) en la postulación kantiana de esquemas conceptuales básicos universales; 2) en la presuposición complementaria (realismo empírico) de que en la base de la atribución de la verdad, aun cuando esa atribución sólo se otorgue a secuencias lingüísticas, están los propios hechos, esto es, instancias cuya realidad, una vez que ya tiene perfiles lingüísticos en absoluto, es independiente de las creencias de un sujeto, de una comunidad, o de una generación; 3) y, por último, en la confianza en normas morales irrestrictas $y$ en intereses básicos, confianza que, en conjunción con el primer punto, determina una suerte de personalidad humana o autoconciencia primaria común. La propuesta de deflación conceptual no desea, expresamente, escudarse en el acierto de sus reparos, ni en la real naturaleza de cada yo, ni en claras razones morales. Se nos dice que ticne sólo una base pragmática, como base última. No está ahora en mi intención restaurar las dignidades mayúsculas de las abstracciones controvertidas. Pero como la alternativa al restauracionismo no es sólo la republicana deflación, las objeciones antideflacionistas que deseo exponer a conti- 
nuación no están atadas a un compromiso de fidelidad al viejo régimen.

2. El episodio central de la ofensiva pragmatista ha sido su teoría de la verdad, como peculiar postergación de la propia noción de verdad, en tanto noción básica, en beneficio de nociones como eficacia, utilidad y satisfacción, juzgadas más conspicuas. Adicionalmente, la concepción pragmatista ha proporcionado una afilada crítica del realismo metafísico, en la medida en que ha socavado la representación del acceso a verdades como un procedimiento pasivamente reduplicativo, haciendo ver que cada verdad incluye, respecto a una reduplicación icónica, una activa adición, que recompone en primer lugar el desparramo de lo dado. A la muchedumbre caótica de los estímulos sensibles se añade algo para establecer un primer concierto. Lo que se añade son requisitos que hacen posible la formación en absoluto de creencias, deseos e intenciones. Éste es un trámite obligado, independientemente de que luego arribemos a creencias acertadas, o deseos e intenciones factibles, o decaigamos en el error o en la ilusión. Otro mérito notable del pragmatismo es su contribución al descrédito de ciertas metaforas canónicas acerca de la Verdad: definitiva enciclopedia, por ejemplo, de elaboración en curso, o meta final de un periplo de busca. Para un pragmatista, la verdad presupone, antes bien, una articulación de determinadas experiencias formadas a la medida del orden humano y sometidas al cambio. Al cabo, las más firmes verdades no van más allá de la vida de la especie. Si en lugar del tiempo histórico imaginamos un tiempo cósmico, donde el sistema solar nace y muere, no hay hazañas cpistemológicas.

Paralelamente a todo ello, en alguno de los más insignes pragmatistas encontramos también, en contraste con Rorty, una amistosa conciliación entre su oposicion a todo realismo metalisico y el realismo empirico, si por éste entendemos, a tenor de nuestra reconstructiva sugerencia precedente, un postulado de independencia de proposiciones. La verdad, como atributo de enunciados, supone una concxión entre objetos, cuya identidad depende de redes descriptivas, y sujetos cognoscentes y comunicativos, que en calidad de tales dependen de instancias extrasubjetivas que no se complacen con todas sus veleidades. Esa falta de complacencia se revela en el hecho de que creer en algo no determina, por lo general, que lo que se cree sea verdad. ${ }^{3}$ El único contenido que podríamos ligar a una teoría de la correspondencia de la verdad es, precisamente, la independencia de la verdad de muchos de los enunciados que expresamos respecto a nuestra creencia respectiva. A mi entender, éste es todo el intringulis del realismo empírico y bajo esta formula está expresamente reconocido por el pragmatismo clásico, que únicamente se opone a un modelo ingenuo de verdad por correspondencia." La correspondencia misma sería asi un tipo de postulado, adicionalmente apuntalado con indicios. Entre los clásicos pragmatistas, una proposición verdadera es una proposición tal que el asentimiento a ella es un medio eficaz de localización o anticipación de experiencias sensibles. ${ }^{10}$ Reconncer la verdad de esa proposición facilita el cálculo o previsión de experiencias, así como intervenciones para la obtención o elusión de tales experiencias. ${ }^{11}$ En tal caso, esta suerte de eficacia es el indicio de la correspondencia. El punto sutil, ahora bien, cstá en que, a la luz de la enseñanza que contiene la crítica al realismo metafísico, ninguna experien- 
cia sensible justifica la eficacia del cálculo o la intervencion: en todo caso, lo que la puede justificar es un informe acerca de esa experiencia. De modo que, al socorrer con este indicio a la postulada correspondencia, no añadimos un momento de genuina confrontación entre la proposición primera y un episodio no verbal.

A partir de este sutil punto, Rorty ha querido extraer enseñanzas radicales: dado que esa confrontación no es posible, la eficacia, la utilidad o la satisfaccion ligadas a nuestras empresas cognitivas no serían indicios de una correspondencia con la naturaleza de las cosas. En rigor, no serian criterio alguno de verdad; simplemente desplazarian a la verdad. A tenor de nuestras consideraciones del inicio, un imaginable modo de reconstruir algunas de las tesis capitales que comparten los criticos del realismo metafisico es unificarlas bajo el principio de que la verdad es un predicado de proposiciones, cuya correcta atribución sólo puede ser asegurada con el concurso de otras proposiciones. No hay eventos extralingüísticos autovalidantes. Si concebimos la correspondencia en el otro más sobrio sentido realista que hemos expresado luego (esto es, como mera invocación vinculada a la cisura que media entre las creencias actuales de un sujeto, o una colectividad de sujetos, $y$ la verdad de esas creencias), entonces hemos de concebir generalmente a cada creencia empírica singular como básicamente enmendable. Mas como la enmienda de las creencias de otros, apele a lo que apele, adopta forma proposicional, esa enmienda ha de presuponer un esquema conceptual común, que los descarriados comparten con sus objetores, y que es un prerrequisito tanto de la imputación del error, como de la declaración de consonancias. Por esto, propiamente, esa fórmula de rea- lismo empírico que hemos propuesto y la moderna abstracción de la Razón, o de un esquema conceptual básico común, son dos caras de una misma intuición. Cuando afirmamos que eso que alguien cree o creyó, por más que lo crea o lo haya creido, es falso o desacertado, sobreentendemos que hablamos en marcos conceptuales conmensurables, porquc sin esa conmensurabilidad no se abre cauce alguno a la determinación del error. Situándonos aquí, se entiende mejor el paso más allá que avanza Rorty, porque su alegacion clave en este punto es la de que fuera de cada cerrado espacio comunitario (paradigma, colectividad histórica, tradición particular, civilización...) no habría metacriterio alguno para la apreciación racional de creencias, o sistemas de creencias, desarrollados en el espacio dado. Por consiguiente, el principio mismo del realismo empírico (la real enmendabilidad de las creencias) no tendría aplicación al margen de un espacio particular y, en esa medida, las abstracciones on cuestión resultarían desbaratadas.

Claro es que Rorty cnarbola esta tesis radical precisamente frente a un sistema de creencias asociado dircctamente al cerrado espacio historico que, por medio de las controvertidas abstracciones mencionadas, conforma aún el actual espiritu de los tiempos. ¿Y no es éste un signo clave de presuposicion de conmensurabilidad interparadigmática? "Desde el punto de vista de la filosofía que estoy proponiendo, no se deberf́a pedir a los filosofos argumentos contra, por ejemplo, la teoría de la correspondencia de la verdad o la idea de la "naturaleza intrínseca de la realidad". La dificultad que envuelve a los argumentos contra el uso de un vocabulario respetado por costumbre durante mucho tiempo es que se espera de ellos que sean expre- 
sados en ese mismo vocabulario. Se espera de ellos que muestren que elementos centrales en ese vocabulario son "inconsistentes en sus propios terminos", o que "se deconstruyen a sí mismos". Pero eso no puede nunca ser mostrado. Todo argumento con objeto de mostrar que nuestro uso familiar de un término familiar es incoherente, o vacuo, o confuso, o vago, o "meramente metaforico", tiene que ser inconclusivo e incurrir en petición de principio, puesto que tal uso es, después de todo, el paradigma de discurso coherente, significativo y literal. Tales argumentos obran siempre como parásitos y abreviaciones de la pretension de que se haga disponible un nuevo vocabulario. ${ }^{12}<C 6$ mo procedería entonces su filosofía? Como lo hacen los políticos utópicos y - Thomas Kuhn dixit- las ciencias revolucionarias; introduciendo redescripciones radicales de las cosas hasta crear un nuevo modelo de lenguaje, que se intenta que la nueva generación adopte. Siguiendo este procedimiento, se sugiere que la vieja forma de hablar sea abandonada, pero no se arguye a favor de esta sugerencia apeIando a criterios comunes al viejo $\mathrm{y}$ al nuevo lenguaje. En cuanto que el nuevo lenguaje es realmente nuevo, no hay tales criterios comunes. La filos 6 fica "cultura post-filosófica" que Rorty promueve frente a la vigente cultura $y$ su repertorio de abstracciones no sería, por lo tanto, más verdadera, racional, o acertada que esta última. Sin embargo, el sentido de sus sugerencias y recomendaciones está en que adoptemos esa "cultura" o lenguaje alternativo, y la fuerza motivacional requerida para movernos a esa adopción tiene, se nos dice repetidamente, solo un fondo pragmático: el interés de un lenguaje o aparato conceptual innovativo -un producto de abducción, una creación "poética"- está relacionado con su contingente eficacia como instrumento. ${ }^{13}$ De este modo, la objeción que debiera motivarnos a abandonar los presupuestos del realismo empírico, o el "vocabulario kantiano" en moral y el "vocabulario cartesiano" de la autoconciencia, sería la de que "la tradición cultural a la que pertenecen no ha dado resultado, crea más dificultades que ventajas». ${ }^{14}$

3. La característica debilidad general del pragnatismo clásico estaba ligada a su apreciación de lo que estimaban como indicio capital de correspondencia veritativa: la eficacia, la utilidad, la satisfaccion... A la postre, la verdad se reducía a una maximalización de tales indicios. La radicalización de la posición de Rorty entraña un abandono del postulado de la correspondencia $y$, en relación con ello, una disolución de la misma noción de verdad en beneficio de esas otras nociones. Pero la objeción capital a la que era sensible aquel viejo programa de reducción de la noción de verdad, afecta igualmente al nuevo programa de disolución: "eficaz" (como "útil", "satisfactorio", "bueno o mejor para", "ventajoso", "funcional"...) es un atributo secundario en relación al atributo "verdad". La eficacia de algo, dado un fin cualquiera, ha de ser verdadera, no fantástica. Dicho en otros términos: si intentamos que se ratifique en un proceso de discusión la eficacia máxima del asentimiento a cierta proposición (o sistema de proposiciones), bajo el supuesto de que la verdad de esa proposición no es otra cosa que esa eficacia, nos valemos de alegaciones que pretenden, cuando menos, ofrecer una motivación oportuna para esa ratificación, pero ésas son alegaciones en las que la función disolutiva de la noción de eficacia se ha desconectado de la pretension motivacional de las propias alegaciones. $\mathrm{Ni} \mathrm{cl}$ 
registro aseverativo de aquella eficacia máxima, ni las alegaciones que secundan a ese registro, pretenden motivar por su propia eficacia la ratificación de la eficacia de la creencia en aquella proposición. La pretensión de que la eficacia de esa creencia sea ratificada es solo la pretensión de que es verdad que es eficaz creer en esa proposición. En tanto es así, la eficacia (así como sus más conocidas nociones cognadas) no es un buen recurso de reducción de la noción de verdad, ni un apoyo seguro tras su desarraigo, toda vez que sea lo que fuere lo que se dice que es eficaz, ha de ser aun verdaderamentte eficaz. Extremo decisivo es que ninguna declaración de intenciones puede sortear este compromiso: alegaciones como las mencionadas tienen pretensiones de validez, se declare o no lo contrario, y no hay forma de disolver definitivamente las condiciones de su validez con el recurso de parámetros pragmáticos. La oposición de Rorty a las más familiares abstracciones ilustradas (las nociones de Razón, de Principio moral, de un esquema conceptual básico, de una personalidad genérica, el realismo empirico...) intenta adicionalmente encontrar socorro en la oscura tesis de que el lenguaje es un tipo de evento contingente. Esta tesis se enfrenta a graves problemas. Si el lenguaje como un todo es contingente. hay algo que no sea contingente? Si lo hubiera, no es algo preciso de lo que pudiéramos decir que no es contingente. En ese caso, nada podríamos identificar caracterizadamente como no contingente. Pero una contingencia tan abarcadora es enteramente vacua. Por razones asociadas a esto, la tesis de la contingencia del lenguaje como un todo nos puede llevar a otro enredo: "contingente» es un predicado, articulado a través de su oposición al predicado "necesario", pero de esta oposi- ción no se predica ni la contingencia, ni la necesidad. $Y$ siendo así, ¿cuál es el sentido de decir que el lenguaje al que pertenecen esos predicados es contingente $-o$ necesario? Claro es que esa contingencia puede ser entendida de otras formas. Cuando no haya hablantes de ningún lenguaje, tampoco habrá, desde luego, verdad o creación conceptual alguna. $\mathrm{Y}$ en ese general sentido, toda verdad $\mathrm{y}$ abducción $\mathrm{y}, \mathrm{a}$ fortiori, todo lenguaje, son ciertamente contingentes: dependen de la casual existencia de seres capaces de hablar. Por relación al lenguaje como un todo, esta contingencia es también trivial. Esta no es, ahora bien, la posición de Rorty. La tesis rortyana de la contingencia del lenguaje da por asentada una pluralidad de lenguajes: la contingencia seria primordialmente un atributo de cada uno de esos lenguajes. Ello sugiere que el fondo de la tesis de que el lenguaje es contingente es la espontaneidad de cada creación conceptual y la decisiva contigüidad temporal de nuestras concepciones con creaciones antecedentes, paralelas y posteriores. La contingencia de lo que se nos ocurre y del horizonte temporal de nuestras ocurrencias es indisputablc, pero no brinda a Rorty un adecuado estandarte para batallas relativistas realmente dramáticas. El curso de la historia de las creaciones conceptuales de la humanidad hubiera podido ser otro $\mathrm{y}$, en tanto es así, sus episodios son contingentes. Eso no implica, sin embargo, que distintos de esos episodios, o distintos de esos cursos, sean inconmensurables (con el paso del tiempo, inaccesibles a la interpretación).

En opinión de Rorty, de todos modos, la tesis en cuestión tiene importantes corolarios. Según uno, muy consecuente con la tesis, cada argumento y cada principio moral padecerían la misma contingencia que el lenguaje al 
que pertenecen. Según otro, la dualidad entre lo racional y lo irracional, o la recta y la mala conducta, sólo cabría ser establecida, en rigor, en el seno de un lenguaje determinado. Esas dualidades no serian, pues, adecuado punto de referencia para la comparacion y apreciación de distintos lenguajes. Mas dados los términos en que viene dada la tesis de la contingencia del lenguaje, no es nada obvio que podamos concluir este segundo corolario. Es un hecho contingente, por ejemplo, que yo formule precisamente en este momento una objeción a Rorty. También es un hecho contingente que Rorty haya concebido sus ideas. Que yo haya concebido mis objeciones es entonces al menos doblemente contingente. Bien se entiende que estas contingencias se multiplican sin limite bajo otras consideraciones. Pero de esto no se deriva la inconmensurabilidad del marco de las ideas de Rorty y el marco de mis objeciones. De la contingencia de cada concepción de un sistema de ideas no se sigue que cada concepción determine reglas de su propia validez en forma tal que esas reglas no sean accesibles a la crítica de concepciones opuestas.

Por otro lado, el contenido de ese segundo corolario es de por sí endeble. Su defensa se desbaratará tan pronto como deje paso a alegaciones a favor de la preferencia por "un lenguaje» dado: por ejemplo, a favor del marco conceptual en el que se afirma la contingencia de cada marco conceptual y la inconmensurabilidad de esquemas conceptuales alternativos. Ahora bien, no cabe defender ese corolario (promover su aceptación) sin alegaciones de ese tenor. Según el corolario en cuestión, no sería posible, por ejemplo, justificar a la sociedad liberal frente a otros tipos históricos de organización social. La sociedad liberal no podría confiar en su propia justificación. Así pues, como genuino producto de la Ilustración habria, al cabo, de ser redescrita libre de las abstractas invocaciones de la propia Ilustración. Sin embargo Rorty, en atención a los presupuestos de ese mismo corolario, de hecho encuentra alegaciones a favor de la preferencia por la sociedad liberal. La proliferación de "mutaciones conceptuales" sería, en efecto, muy deseable bajo el supuesto rortyano de que es la eficacia contingente de una de esas mutaciones la que debe en cada ocasión motivar su adopción. La indirecta alegación final a favor de la sociedad liberal se basaría, por eso, en la conexión de sus ideales con el fomento de la proliferación. ${ }^{15}$ ¿Y no es esa alegación una alegación a favor de una elección racional, o a favor de una recta conducta?

Este último es sólo un escueto indicio de todo lo que Rorty se ve compelido a hacer en contra de lo que dice. Imaginemos que sus escritos no tuvieran, tal y como él subraya, ninguna pretensión de validez y que Rorty no presentara alegaciones, no intentara convencemos: esto es, I) que no intentara producir en el lector nuevas creencias en virtud del reconocimiento del lector de su intención de producir en el esas creencias en gracia al reconocimiento de su intención de producirselas con lo que escribe; o II) que teniendo esa intención, no se cumpliera la doble condición de que esas creencias sean creencias del propio Rorty y de que tanto Rorty como el lector que adquiere esas creencias crean que lo que escribe Rorty es razón para adquirir o conservar esas creencias. La intención de Rorty de producir en el lector un cambio de creencias es, en cualquier caso, poco controvertible. Como se cumple este requisito intencional, pero no alguno 
de los restantes que son precisos para tener una genuina intencion de convencer, podría decirse que la intención de Rorty de producir creencias en el lector es solo "persuasiva", entendiendo por ésta la intención, distinta a la de convencer, que calacteriza, por ejemplo, a un discurso puramente retórico. Pero una vez vislumbrado esto, se entiende muy bien por qué Rorty es repetidamente autocontradictorio, por qué, contra sus propósitos expresos, se ve compelido a presentar alegaciones, a comprometerse con intenciones de convencer. Le ocurre igual que al buen retórico: para producir una creencia en su audiencia, el buen retórico ha de ocultar que su intención es puramente retorica, que el no cree lo que quiere que otros crean, o no cree que lo que dice sea razón para adquirir esa creencia. La intención retórica es inevitablemente un parásito de la intención de convencer. Como Rorty no renuncia a la intención de producir creencias, presenta inevitablemente alegaciones que adoptan la forma intencional requerida para la producción de un convencimiento genuino. La repetida adicional declaracion de intenciones contrarias a la intención genuina de convencer produce entonces un efecto chirriante. Si, en efecto, las apelaciones de Rorty no quisieran convencer a su lector, ¿por qué habrian de ser consideradas interesantes? Pero si, por el contrario, quieren hacerlo, resultan entonces poco convincentes: son apelaciones contradictorias.

\section{Humanidad}

1. Como he dicho, una de las abstracciones ilustradas rechazadas por Rorty es la representación de una personalidad básica universal. Esta personalidad común, por firmemente que se diera por supuesta, estaba en una de las cumbres de la Ilustración, la filosofía kantiana, marcada por una opacidad conceptual: la opacidad del yo. YO (como ahora y aqui) es un peculiarísimo designador rigido. ${ }^{16}$ Mientras que los nombres propios, como designadores rígidos, sólo nos facultan la identificación de los objetos que designan en tanto están secundados por formas aspectuales, por descripciones, YO nos puede identificar aun en el caso en que lo imaginemos inicialmente desprendido de toda forma aspectual. Los restantes objetos, una vez desprovistos de formas aspectuales, se convierten en noumenos inasequibles. Pero YO es un designador especial. Si pierdo toda memoria propia, al preguntarme quién soy yo, YO me designa precisamente a mí, por más que de mí no sepa otra. cosa que yo me pregunto quién soy yo. Podemos creer, igualmente, que somos alguien que no somos. Puedo, por ejemplo, creer que soy Napoleón. Mas en este aturdimiento YO no ha dejado de ser denotativo. Respecto a YO, los nombres propios son por eso sólo caracterizaciones. Los restantes pronombres personales no comparten estas peculiaridades de YO. Nos cabe imaginar que alguien está ahí, e interpelarle como TÚ. Ahora bien, puede no haber nadie realmente ahí, y TÚ no designar entonces nada. Con YO no puede ocurrir lo mismo. Para que YO sea denotativo basta tener la intención de autodesignarse, sea cual fuere el contexto de la autodesignación. Puedo dibujar un plan de juego en el papel. Digo, entonces, que este punto eres tú, este otro al y este tercero soy yo. Si estoy solo en la habitación, no solo este punto no eres realmente tú; no hay ningún objeto que TÚ designe. Pero aunque yo no soy en realidad ese punto, yo soy. Acerca de mi identidad personal puedo engañar, fantasear, hablar imaginativamente. En cada caso lo que digo que 
soy (como mentiroso, como actor, como imaginativo planificador, como espiritu aturdido...) no es lo que soy. Pero al decir que yo soy eso que no soy, con YO me he identificado propiamente.

Claro que de todo esto podría también sacarse la cnseñanza contraria. ¿No sucedería asi que cabe siempre un uso apropiado del término YO, aunque no sea posible asociar a ese término ninguna forma aspectual, precisamente porque ese término, cuando está libre de toda forma aspectual, no es un término genuinamente denotativo? En cierta forma, ésta es justamente la tesis que mantuvo Kant respecto a cierto nivel del YO libre de formas aspectuales: el YO que acompañaría como "yo pienson a todas nuestras representaciones. ${ }^{17}$ Este YO precisamente no seria sustancia, Kant observó que nuestra entera visión del mundo viene dada en oratio obliqua: tiene la forma del "yo pienso que... ${ }^{18}$ Extensivamente podemos decir que tiene también la forma del "yo creo que...», "yo dudo que...", "yo deseo que...", "yo intento que...", etc... El YO que eventualmente aparece en las cláusulas subardinadas de estas oraciones indircctas es referencial. Pero el YO de los prefijos de estas oraciones no lo es: es un YO performativo. Cada enunciado que formulamos, 0 es contenido de un estado intencional de nuestra conciencia, implícitamente es una oratio obliqua. Si digo que yo soy el legítimo heredero, este YO me identifica como sujeto que tiene, o pretende tener, ciertos derechos. El YO del implicito prefijo "yo afimo", o "yo creon, etc, no tiene en un primer momento una función designativa genuina. Si adquicre luego esa función, ha de presuponer entonces otro $\mathrm{YO}$ performativo, no referencial. En todo acto de autoidentificación, el yo que se identifica no está en la misma dimen- sion de lo identificado. Pienso que yo soy el legitimo heredero, y este YO es el mismo que ese ÉL que alguien pone en duda que sea el heredero legítimo. Puedo aclarar también que quien piensa eso soy precisamente yo, y no otro, y este YO entonces es también ese EL del que alguien piensa que piensa que es el legftimo heredero. Pero en este acto de aclaración el YO que aclara no es, de nuevo, referencial. Dado que cada una de nuestras representaciones del mundo es un acto intencional (un acto de creer, pensar, proponerse, desear que...) el YO que realiza ese acto, según Kant, no sería un genuino objeto de experiencia, sino una condición de toda experiencia: es lo que llama un YO trascendental.

Como condición de la experiencia, ese YO llamado trascendental tiene otros dos rasgos peculiares en la ontologia kantiana: a) Conforma la unidad de la conciencia. En otros términos: conforma proposicionalmente los componentes de la experiencia y enlaza los contenidos proposicionales de las experiencias en narraciones. La más breve de estas narraciones podría tener un único episodio: yo, que he perdido toda memoria de mí, me pregunto quién soy yo. b) El YO del "yo pienso" que acompañaría a todas nuestras representaciones seria en todas las conciencias el mismo. Cada estado de conciencia es el estado de conciencia de un YO particular, con un particular cuerpo. Pero el YO que se hace presente en cada estado de conciencia no tiene un contenido: no equivale a un preciso estado de conciencia que identificáramos, o a un cuerpo que reconociéramos. Sin embargo, según Kant, si bien ocupa un lugar inaccesible a la conciencia, no ocupa un lugar vacio. Kant supuso que en él están enraizadas las categorias racionales propias del género humano. A la luz de 
este rasgo, la idea de una personalidad básica universal en su vertiente epistemológica no serra sino la ya comentada idea de una humana competencia racional por detrás de las variopintas capacidades y logros individuales.

En las ordinarias apelaciones a la autoridad de la razón invocamos algo que todo el mundo tiene y que nadie puede tener en exclusiva. Al hacerlo, no damos ni un contenido, ni una estructura precisos a esa posesión común; una parte del recelo hacia esa abstracción la provaca, sin duda, esta imprecision y sus etéreas resonancias. En atención a a) cabe sugerir un modo simple, sin embargo, de reconstruir esta abstracción: identificar la competencia racional básica de cada sujeto con su competencia como intérprete. Esa competencia será genuinamente un atributo genérico si son posibles a escala planetaria acuerdos básicos en la interpretación de emisiones linguísticas. Para justificar la generalidad de la competencia racional basta entonces justificar una intertraducibilidad general. Esta intertraducibilidad no es sino una unidad básica de interpretación del lenguaje: el supuesto de que llegamos, o podemos llegar, a acuerdos acerca de la interpretación que hemos de dar a las emisiones de otros y el supuesto de que los demás llegan, o pueden llegar, a acuerdos de interpretación de nuestras propias emisiones. Los expresos desacuerdos de interpretación no contravienen a estos supuestos; por el contrario, los refuerzan: tales desacuerdos no son posibles más que bajo la base de un acuerdo de interpretación acerca del desacuerdo de nuestras interpretacioncs. Toda la sustancia metafísica de las abstracciones epistemologicas ilustradas se hace asi muy transparente. $\mathrm{Y}$ todas las acometidas de Rorty contra esas abstracciones se pueden concentrar así sobre el su- puesto de una básica unidad posible de interpretación del lenguaje. Vistas de este modo las cosas, la más relevante prueba empirica de la personalidad humana básica sería en este punto la intercomunicación que de hecho articula a todas las empresas colectivas de alcance planetario (en particular, el comercio y las aplicaciones técnicas de la ciencia). La cuasi ilimitada implantación de esas empresas no serfa posible sin una básica consonancia en la interpretación del lenguaje. La prueba conceptual es más compleja y en ella se habría de incluir la propia justificación del realismo empirico y de la consiguiente irrestricta enmendabilidad dialógica de la mayoría de las creencias. He apuntado a ese propósito los graves inconvenientes en que se enzarza al relativismo lingüístico de Rorty. Pero sobre este extremo no tengo aquí ocasión de extenderme más.

2. La representación ilustrada de una personalidad básica universal posee también una vertiente practica: atribuye unos intereses básicos a todo hombre e imagina principios morales universales. El supuesto de que hay una tal personalidad moral resulta controvertido tanto si se niega que haya tales intereses, como si se niega que haya principios morales que tengan autoridad sobre todo sujeto. La apelación a estos principios padece una vaguedad análoga a la que padece la apelación a la Razón. Para los ilustrados una apelación y otra eran de hecho la misma. He querido sugerir que el peso mctafisico de las apelaciones a la Razón se aligera cuando el contenido de esta abstracción se reduce a una posible unidad de interpretación del lenguaje, a un acuerdo básico de traducción. Cuando esas apelaciones tienen una indole práctica, un análogo aligeramiento se produce si en su lugar nos 
remitimos simplemente a una posible unidad básica de interpretación de las emisiones morales. Un acuerdo en la traducción de una emisión equivale a un acuerdo en la atribución de las condiciones de verdad, validez o satisfacción de esa emisión, aumque no equivale a un acuerdo acerca del cumplimiento o incumplimiento de esas condiciones. Según csto, un acuerdo en la traducción de una emisión moral habría de arrastrar consigo un acuerdo normativo, toda vez que las condiciones de validez de esa cmision han de incluir una norma. Eso quiere decir que la justificación de una unidad básica de interpretación del lenguaje moral requeriría acreditar un compromiso de todo juez moral con alguna norma primaria de relevancia moral. Sobre este punto no diré tampoco nada aquí, pero sî diré algo sobre intereses básicos.

Las reservas de Rorty ante la idea de un YO práctico básico guardan una significativa ambivalencia. Por una parte, Rorty no percibe en las apelaciones a la comunidad irrestricta de los «hijos de Dios» o de los "seres humanos» más que ensoñaciones filosóficas y reduce la posible fuerza motivacional de una apelación moral a las áreas cubiertas por lazos como los que ligan a los americanos entre sí, o a los católicos entre sí, o a los miembros de la tribu entre sí...; áreas que mantienen su cohesión interna sólo en tanto que abren una brecha entre quienes las habitan y quienes están fuera de ellas, entre «nosotros» y «ellos». Paralelamente, sin embargo, Rorty promueve vehementemente el desarrollo de una virtud que atribuye a la sociedad liberal: la solidaridad. Una virtud que, afirma regocijado, tiene que encarecer cn tanto que ya no puede dejar de ser lo que contingentemente es: un ciudadano occidental moderno. ${ }^{19}$ "[...] No concibo esa solidaridad - dice- como reconocimiento de un yo nuclear, como una esencia humana en todos los seres humanos. La concibo, antes bien, como la capacidad para considerar fútiles cada vez más diferencias tradicionales (de tribu, religion, raza, costumbres, etc.) al compararlas con las similaridades respecto al dolor y la humillación: la capacidad de concebir a gente extremadamente diferente a nosotros incluida en el alcance de "nosotros". ${ }^{20}$ Rorty observa perspicazmente que la literatura narrativa tiene la peculiar facultad de hacer posible la percepción de esas similaridades.

Hemos dicho que una parte de la sustancia ontológica de la abstracción ilustrada de un YO práctico universal es un simple postulado de intereses básicos. Ahora bien, este postulado es inexcusable para toda moral de principios universales o de virtudes de aplicación no restringida. El desarrollo de la solidaridad, como extension de nuestros deseos altruistas - deseos que se satisfacen con la simple satisfacción de los deseos de los otros- más allá de nuestro contingente ámbito comunitario inmediato, presupone por eso también una base de intereses comunes. El extremo clave ahora no es si debemos promover la solidaridad no restringida o ser solidarios; el extremo clave es que toda solidaridad presupone una comunidad de intereses básicos. Esos intereses básicos o bien son intereses negativos, como los que menciona el propio Rorty, o una suerte de metaintereses. Los intereses de primcr orden tienen desde luego la misma contingencia que el punto temporal y lugar de desarrollo de la vida de cada uno. Pero los intereses básicos no padecen esa misma contingencia. Como intereses negativos, se oponen a las más familiares calarnidades y desgracias (muerte, dolor, humillación, aban- 
dono...). Como metaintereses, conforman proyectos vitales. Emparejándolos con sus contrasombras hablamos de autosatisfacción $\mathrm{y}$ autodescontento, autorrespeto y autodesprecio, complacencia y frustracion...

Presuponer una básica personalidad humana conformada por intereses básicos es característico, como decimos, de las expresiones más evolucionadas de universalismo moral. Todo igualitarismo practico atañe a la significación moral del conjunto de intereses de esta indole: dice que talento, posición social, raza, nacionalidad, etc., no modificarian el rango intersubjetivo paritario de tales intereses. Su lesión tendría la misma importancia en cada caso. ${ }^{21}$ Así, por ejemplo, la base igualitaria de la idea de justicia propuesta por Rawls está cimentada sobre una concepción de "persona moral" que atribuye a ésta lo que Rawls ha llamado wintereses del más alto orden", al igual que el interés por "bienes primarios" que son requeridos para el cumplimiento de esos intereses. ${ }^{22}$ La distinción entre los metaintereses básicos de todo sujeto y los intereses particulares que cada sujeto adquiere al ritmo de los avatares de su vida es sin duda un rasgo de marca del proyecto de Rawls, pero el cuño de la postulación de intereses básicos es ya de larga Techa.

Un cjemplo histórico eminente lo proporcionan las diversas formulaciones históricas de la regla de oro. Las más corrientes objeciones a la regla de oro se han dirigido precisamente contra cierta versión limitada del contenido de la postulación de esos intereses. En otra versión más generosa, sin embargo, el buen sentido de la máxima de que sc debe tratar a los demás como uno desearía ser tratado por ellos no conmina, por ejemplo, al masoquista a ser un sádico, sino que abstrac precisamente las diferencias de las puntuales preferencias individuales para remitirse a un tipo general de metapreferencias compartidas. La aplicación de esa máxima tampoco requiere una monótona nivelación de las variopintas personalidades individuales. Al contrario, se apela a la máxima en cuanto que una reconocida abigarrada conformación de intereses y necesidades individuales genera eventualmente conflictos intersubjetivos. Mas para dirimir esos conflictos que han sido producidos por las diferencias individuales, la máxima nos prescribe una visión imparcial desde un imaginado plano de personalidad unitaria, Es bien sabido que la tradición utilitarista está ligada a presupuestos análogos de modo también muy explícito. Los cálculos de la utilidad social dan por sentada la posibilidad de comparar interpersonalmente las preferencias individuales en una escala común. ${ }^{23}$ En la versión habermasiana de la ética discursiva esos mismos presupuestos están relacionados con el puesto eminente que en esa ética --.bajo la influencia en este punto de George Mead- ocupan los procedimientos de role taking. ${ }^{24}$

En éstas, como en otras bien conocidas expresiones de universalismo moral, el juez moral ha de apreciar un valor ponderable en las preferencias de cada parte afectada. La ecuanimidad es en estos casos un rasgo constitutivo de la propia acción judicativa. Según nuestra actual intuición lingüística predominante este fenomeno se manifiesta en que todo juicio moral genuino ha de ser precisamente extensible por principio a todos aquellos casos idénticos al caso apreciado en sus propiedades universales; es decir, si ponderando los intereses de todos los sujetos afectados prescribo a alguien un curso de acción justa no puedo en circunstancias análogas substraerme yo mismo a la prescripción sólo "por ser 
quien soy", renunciando, p. ej., a apelar a rasgos de esas circunstancias, de los intereses de los otros sujetos afectados y de mis propios intereses que ahora conformen otra clase de casos. Para apreciar el valor de las preferencias ajenas no puedo sino remitirme a mis preferencias propias, pero los juicios morales nos comprometen con un grado de abstracción bajo el cual como jueces morales ponemos entre paréntesis a aquellas de esas preferencias que justamente nos distinguen de los otros. Merced a esa abstracción, dada mi preferencia por el vino tengo la base de interpretación suficiente para apreciar las preferencias de otros por la naranjada.

Para llegar a desarrollar solidaridad por otros -un decisivo interés por el interés de los otros- es preciso percibir en la particular suerte de los otros el quebranto de cierto nivel de preferencias que también nosotros poseemos. Yo no tengo la preferencia que el minero amenazado de despido tiene acaso por su trabajo en la mina. Pero puedo tomar interés por su preferencia en tanto que tal vez comparta con él la preferencia por conservar el puesto de trabajo, o por tener una fuente estable y suficiente de ingresos, o por salvaguardar mis planes de vida más enraizados, etc. Cuanto más lejana a nosotros es la órbita vital del otro, tanto más generales son las preferencias que estimamos al solidarizarnos con él. Cuando realizamos una apreciación moral siguiendo el conocido procedimiento de "ponernos en la situación de los otros", damos por entendido que podemos estimar el valor de las preferencias de los otros a pesar de nuestras actuales preferencias. El tipo de abstracción que esto implica no es sólo propia del contexto moral; está asociado en realidad también a la apreciación reflexiva de nuestras pro- pias preferencias. Siempre que realizamos apreciaciones prudentes en atención a nuestros posibles deseos futuros abstraemos nuestros deseos actuales de un modo semejante: nos ponemos en una situación en la que aún no estamos. Una situación análoga es también la aún más compleja en la quc, para tomar una decisión racional, apreciamos no sólo las posibilidades de que sean satisfechas nuestras preferencias actuales y nuestras previsibles preferencias futuras, sino también las posibilidades de que fueran satisfechas las preferencias que se llegaría a tener si adoptáramos otras preferencias actuales. Tanto el desarrollo de actitudes solidarias, como las apreciaciones prudentes y las apreciaciones hipotéticas y morales requieren un autoconocimiento de nuestras disposiciones volitivas. Resulta claro que el grado de autoconocimiento que el juez moral ha de tener es muy general. Sabemos que en la metafísica ilustrada se supone que es el conocimiento de sí mismo como "ser humano». He intentado hacer ver que esta "humanidad esencial" no es en este punto otra cosa sino la base común de abstracción de las preferencias que es requerida para la realización de un juicio moral, o para adoptar una decisión racional, o para solidarizarnos.

Entender bien el grado que posee esa abstracción cs importante. Su grado es poco compatible con un atomismo de las preferencias que se halla frecuentemente asociado al utilitarismo cardinal. Ese atomismo, en efecto, aprecia preferencias puntuales y abre cauce entonces a preguntas del tipo de si su disfrute de la música es más intenso que mi disfrute de la siesta. Ponerse en la situación de otros consistiría entonces en apreciar el vigor de sus preferencias. Fl sentido del postulado de una personalidad práctica básica se 
transmutaría en el postulado de algún sistema para el cálculo de la intensidad de las preferencias. Esto plantea muchos problemas. Si hemos de conceder un único bien no divisible a $\mathrm{Fu}$ lano o a Zutano, de forma que la concesión de ese bien no afecta en ningún sentido a los intereses de algún tercero, la acción moralmente preferible para un utilitarista de ese tenor sería aquella que da satisfacción a la preferencia subjetiva más intensa. Si nos concentramos en la connotación más inmediata del término sintensidad" en este contexto, comprobamos que en nuestros juicios morales ordinarios la intensidad actual de las preferencias no es sin embargo el criterio último de apreciación.

De no ser así, los apáticos, los lánguidos, los que momentáncamente apenas se toman en consideración a sí mismos (por generosidad, o por falta de autorrespeto), o los pesimistas ontologicos que han planificado una aminoración de la vehemencia de sus preferencias (tal vez con técnicas budistas de autocontrol, tal vez con lecturas reiteradas de Schopenhauer) resultarían siempre desfavorecidos en las decisiones judicativas o en las acciones solidarias, para beneficio de los temperamentos alegres o entusiastas. Siempre que no resulten postergados habrá que pensar, en cambio, que las metapreferencias comunes que han orientado el dictamen del juez o el acto de solidaridad determinan en el juez o actor sólo rangos de preferencias. La vaporosa métrica de las intensidades queda fuera de lugar. ${ }^{25}$

Problemas más serios aún son los que se derivan de la independencia que ese atomismo tiende a conceder a cada preferencia. Esa independencia es cuestionable por variadas razones. Puedo, en efecto, decir coherentemente, con descngañada melancolía, que disipe mi juventud con joviales frivolidades, o al contrario, puedo encomiar el valor que en la formación de mi carácter, o de mi visión del mundo y de la vida, han tenido ciertas tempranas ásperas vivencias. Aún más: en cada momento temporal nos cabe reconstruir nuestro pasado. Esto no es, contra lo que podría parecer, una falacia, o una posibilidad sólo abierta a la falsa conciencia o al autoengaño. ¿Cuál es la infancia y juventud de Jean Genet después de escribir Diario de un ladrón? ¿Y cuál era antes de que lo escribiera? En un caso, el pasado de Genet es razón necesaria de Diario de un ladrón; en el otro caso no existe ese curso causal. ¿Cómo es mi pasado después de abandonar la pasión dominante que lo guió, o después de descubrir en sus sombras un reflejo de sentido? Pero si es posible devaluar o revaluar nuestras viejas preferencias no es posible, entonces, una apreciación independiente de cada sucesiva preferencia local: Diriase también que el sentido de dar una nueva valoración a nuestras preferencias pasadas está a la base a su vez de nuestra depreciación (o repreciacion) de las preferencias ajenas, cuando concedemos a esas preferencias menos (o más) valor que cl que le atribuyen momentáneamente sus poseedores. El atomismo utilitarista es igualmente poco congeniable con esto.

La independencia de las preferencias genera aún otra dificultad paralela. Ciertas preferencias actuales entran en conflicto, en virtud de su génesis, con una metapreferencia de autonomia. A preferencias actuales de esa clase Jon Elster las ha denominado preferencias adaptativas. ${ }^{26}$ Se producen cuando para evitar la frustración uno limita indeliberadamente sus preferencias a un conjunto factible de preferencias. Ahora bien, una mujer que supere sus preferencias adaptativas, adquiriendo ambi- 
ción, y que no tenga sin embargo la posibilidad de dar cumplimiento a sus nuevas preferencias, será una persona decepcionada. Cuando no comparte las preferencias de su marido hacia el trabajo y la independencia, la proporción de sus preferencias satisfechas es más alta. Pero cuando adquiere las preferencias de su marido, se hunde en la decepcion. Sin embargo, es probable que esa mujer preficra su actual estado decepcionado al estado previo de adaptación sumisa. El fenómeno es muy frecuente y justifica a todos los movimientos políticos que tienen por fin que un grupo social determinado perciba una desilusión, abandonando sus preferencias adaptativas. El soliviantador social imagina una metapreferencia tácita de todos por preferencias que no estén indeliberadamente restringidas al conjunto de opciones de satisfacción inmediatamente factible (por preferencias, por ejemplo, que se invierten tan pronto como ese conjunto es alterado). Aunque esa metapreferencia misma haya de permanecer insatisfecha, anula el valor de las preferencias adaptativas que eran satisfechas. ${ }^{27}$ El reconocimiento del valor de la autonomia confirma que nuestras preferencias locales pueden ser devaluadas si no se ajustan a nuestras preferencias globales. Ello da muestra de la naturaleza planificadora que tienen algunas de las metapreferencias o intereses básicos del YO práctico. Al recapacitar nuestra historia biográfica, por más que en ella predominen las preferencias locales satisfechas, podemos otorgarle una estimación negativa: acaso no satisfaga a nuestras actuales metapreferencias..$^{28}$ Es este mismo criterio de rango de preferencia el que aplicamos al buscar metapreferencias comunes que guien nuestra apreciación de las preferencias ajenas.

\section{NOTAS}

1. Hulary Putnam, "Why there isn't a readymade world?, en Realism and Reason, Cambridge Univ. Press, 1983, pp. 205-229.

2. P, Strawson abria un catuce a esta alternativa en su ya clásico artículo averdadn $(1950)$, recogido en Ensayos logico-lingulsticos, Madrid, Tecros, 1983 , pp. 216-243.

3. La asociacion cntre causalidad, condiciones necesarias y suficientes, y manipulaciones experimentales y contrafacticas de estas condiciones está, naturaimente, conectada a las reflexiones de G.H. von Wright. Crr. Explicación y comprensión, Madrid, Alianza, 1979, pp. 57-107.

4. Al respecto, ctr. Nelson Goodman, Ways of Worldmaking, Hackett, Indianápolis, Cambridge, 1978, esp. pp. $1-23$ y $91-109$.

5. Cfr. Richard Rorty, Contingency, Irony, and Solidarity, Cambridge Univ. Press, 1989.

6. «Es inconsecuente guillotinar al príncipe y sustituirlo por el principio*, decfa Ortega, quien, como ahora el propio Rorty, afirmaba la existencia de un lazo consanguineo entre la metafísica modema (de la Vendad, los Hechos, la Justicia...) y la metafisica cristiana. El parentesco se manifestaba en lo que la primera tenia de antivitalista, siendo así que evitalismo* es una noción que en la obra de Ortega deja escapar tañidos pragmáticos. Cfr. El tema de ntuestro tiempo, Madrid, Re. vista de Occidente. 1958.

7. En oposición a esta metaforica, el dinamismo pragmatista, con su importante componente falibilista, está notablemente expresado por John Dewey en * The Problem of Truth", en The Midle Works, vol. VI, Londres, Southern Illinois Univ. Press, 1978 , pp. 13-68.

8. Desde Descartes, el campo de la excepcion a esto se encuentra solo poblado por el conjunto de creencias acerca de los estados de conciencia propios que no admiten autoengaño, Con ello se desempareja, por ejemplo, mi consideración de la proposición según la cual tengo actualmente dolor de cabeza de mi consideración de la proposición según la cual tengo un tumor en la cabeza.

9. Ch.S. Peirce, por ejemplo, matiza, sin abandonarlo, el sentido de la verdad por correspondencia en "Truth", Collected Papers, vol, V, Cambridge, MA, Harvard Univ. Press, 1965, p. 388. 398. Véase también el programa de $J$. Dewey resumido en *A Short Catechism Conceming Truth", en The Midale Works, op. cit, esp. p. 10. La siguiente cita de $W$. James es particularmente ilustrativa de la tensión de este punto: "Un hecho 
preexiste virtualmente cuando están dadas todas las condiciones para su comprensión excepto unan. En el caso del número de estrellas que componen la Osa mayor "la condición que falta es el acto de la mente que cuenta y compara. Pero las estrellas mismas (una vez que la mente las considera) dictan el resultado [...]. Tenemos aqui una cuasi paradoja, Indudablemente, con el contar adviene algo que no estaba ahr. $Y, \sin$ embargo, ese algo fue siempre verdad. En un sentido lo creamos, y en otro sentido lo encontramos», The Meaning of Truth. Westport, CT, Greenwood Press, 1971, pp. 93-94.

10. Formulas emparentadas con esta se hallan, por ejemplo, en Peirce, "Truth", op. cit., pp. 393 y 397, y en wow to Make Our Ideas Cleary, en sus Collected Papers, op cit., pp. 257-258.

11. Al respecto, véase igualmente la interesante muestra de pragmatismo continental que ofrece Hans Vaihinger en Die Philosophte des Als $O b$. Leipzig, Felix Meiner, 1911, donde este principio se hace expreso.

12. Richard Rorty, op, cit., pp. 8-9.

13. Ibid, pp. 12 y ss.

14. Idem, antroduction: Pragmatism and Philosophyn, en Consequences of Pragnatisn, Brighton, The Ilarvester Press, 1982, pp. xxxvml.

15. Idem, Contingency..., op. cit., pp. 61 y ss.

16. Que ahora y aquf tienen como terminos indexicales peculiaridades comunes con $Y O$ es algo que ha sido subrayado por Héctor-Neri Castañeda, The Self and the I-Guises, Empirical and Transcendentals, en K. Cramer y H. Fulda (eds.), Theorie der Subjektivitat, Francfort, Suhrkamp, 1987, pp. 105-141.

17. Una interpretación de Kant en esta linea es la que, por ejemplo, ofrece $P$. Strawson en aKant's Paralogisms: Self-Consciousness and the "Outside Observer" ${ }_{\text {, }}$ en K. Cramer y H. Fulda, op. cit. pp. 203-220.

18. Un punto que subraya muy bien Castañeda, op. cit., p. 118 .

19. Rorty dibuja una imagen singular, muy antiweberiana, de las ataduras que imponen las sociedades democraticas modemas a las voluntades de sus miembros. El hecho es que, por al contrario, ninguna convención social nos ata tanto que no podamos desdeñarla (aun a costa de contrariedades). Los posibles lectores de Rorty, a los que el gusta de abrazar con un efusivo uso retorico del «nosotros", no están forzados a ser, por ejemplo, tolerantes liberales. Mas este punto lo hemos de dejar también como observación marginal Rorty expresa ese cuestionable diagnóstico historico con particular énfasis en sus articulos "Solidarity or Objectivity? y she Prionty of Democracy to Philosophy», ambos recogidos en $O b$ jectivity, Relativisn and Truth, Cambridge, Cambridge Univ. Press, 1991, pp. 21-35 y 175-197. Digamos adicionalmente sólo que los sedimentos normativos de la turbulenta historia moderna de las sociedades occidentales incorporan tanto la tolerancja voltairiana como la Sittichkeit nacionalsocialista. Cfr. al respecto las observaciones de K.O. Apel en «Zuruck zur Normalität? -Oder konnten wir aus der nationalen Katastrophe etwas Besonderes geletrt haben?", on Diskurs und Verantwortang, Francfort, Suhrkamp, 1988, pp. $370-475$, esp. pp. 408 y $\$ s$.

20. R. Rorty, Contingency..., op. cit., p. 192.

21. Cfr. Hilary Putnam, The Many Faces of Realism, La Salle, Open Court, 1987, pp. 45 y ss.

22. Véase J. Rawls, «Kantian Constructivism in Moral Theory», The Joumal of Phtitosophy. LXXVII, 9 (1980), pp. 515-572.

23. Cfr, John C. Harsanyi, «Cardinal Welfare, Individualistic Ethics, and Interpersonal Comparisons of Utilitys, en Essays on Ethics, Soctal Behavior, and Scientific Explanation, Dordrecht, Reidel, 1976, po. 6-24. Los diversos utilitarismos catdinales han adoptado también diversas actitu. des hacia esa posibilidad. Pero el punto decisivo ha sido para todos habitualmente cl problema de la apreciación adecuada de las utilidades de otros sujetos. Se querria, por ejemplo, poder distinguit el valor de la satisfacción del deseo de uno de recibir urgente asistencia sanitaria del valor de la satisfacción del deseo de otro de que la tapicerla de su coche no se manche de sangre; o poder distinguir la utilidad social de dos estados sociales óptimos en el sentido de Pareto festados en los que no se pucde incrementar la utilidad de un miembro social sin perjudicar la de otro) tales que en el primero hay esplendorosos ricos junto a desheredados miserables, mientras que en el segundo están ausentes esos extremos.

Creo, por olra parte, que la representación del yo práctico que concibe el utilitarismo cardinal cstá infectada de un pernicioso atomismo de las preferencias. Mas acerca de esto tampoco añadiré nada aqui.

24. Vease J. Habermas, Erlauterungen zur Diskursethik, Francfort, Suhrkamp, 1991, pp. 155 y ss.

25. Esto no debe ser entendido como una objeción al cálculo bayesiano. St tenemos dos prefetencias conflictivas, siendo asi que las acciones que han de dar cumplimiento a esas preferencias no garantizan con toda certeza, exentas de riesgo, ese cumplimiento, para decidimos por un curso de acción u otro hemos de atribuir no sólo un valor de probabilidad al cumplimiento de cada preferencia, sino que también hemos de atribuir un valor a cada preferencia. Ahora bien, al comparar las preferencias de distintos sujetos, lo que se ha de comparar es el rango que cada preferencia tiene en el sistema de preferencias de cada sujeto.

26. Véase Jon Elster, *Sour Grapes -Utilitarianism and the Genesis of Wantsn, en John Chris- 
tman (ed.), The huner Citadel, Oxford, oxford Univ. Press, 1989, pp. 170-189.

27. La metapreferencia de autonomfa es equivalente al segundo winterés del más alto orden. de Rawls: el interes por fomar, construir y revisar uno mismo una concepción de lo que es bueno para uno mismo.

28. Imaginemos el caso de que si me inyectaran una peculiar droga adictiva me hubiera de despertar cada mañana con el intenso deseo de recibir una nueva dosis (el ejemplo es de Derek Parfit, que lo discute con mucha agudeza en Reasons and Persons, Oxford, Clatendon Press, 1984, pp. 497 y ss. ). Ese deseo no sería inmedia. tamente doloroso, y alguien le daria por lo demás siempre rápida satisfaccion. A la larga esto conllevaría una gran cantidad sumativa de deseos locales satisfechos. Según la apreciación atomista de las preferencias, lo recornendable habria de ser crear artificialmente preferencias fácilmente sacjables (crear un Brave New World). Con todo, si alguien diese ese paso, lo más probable es que luego yo deseara no haberme convertido en un drogadicto. Pero dado que este deseo no serfa tan perentorio ni pertinaz como mis matutinos anhelos de droga, el total sumativo sería siempre favorable a la iniciativa de convertirme en un drogadicto. Una consideracíón de las metapreferencias excluye en cambio esta extraña conclusión. Si tanto antes de ser convertido en un drogadicto como después de serlo tengo la metapreferencia de no tener preferencias locales por la droga, por más que estas preferencias fueren satisfechas siempre, la metapreferencia o preferencia global adquiere prioridad sobre esas preferencias locales.

\title{
Los mundos de Nelson Goodman
}

\author{
MANUEL LIZ \\ Universidad de La Laguna
}

La presente nota viene motivada por la reciente publicación en castellano del libro de Nelson Goodman Maneras de hacer mundos (trad. de Carlos Thiebaut), Madrid, Visor, 1990, col. La Balsa de la Medusa.

El título original del libro que vamos a comentar es Ways of Worldmaking. Este título queda perfectamente traducido como "Maneras de hacer mundos», y no como «Maneras de construcción del mundo", "Formas de construir el mundo" o cosas semejantes. Estas últimas traducciones, realizadas en algunos textos, traicionarian por completo el sentido de la obra de Goodman. Por cierto, el resto de la traducción que del libro realiza Carlos Thiebaut resulta asimismo impecable, conservando perfectamente el tono cstilístico del propio autor.
La primera cdición de este libro de Goodman data de 1978. Doce años después, aún continúa siendo novedad.

En realidad, toda la obra de Nelson Goodman tiene la novedad de los clásicos. Estamos ante uno de los filósofos analíticos que más han marcado el desarrollo de la filosofía analítica contemporánea. Sin embargo, Goodman es un filósofo heterodoxo y fronterizo. Su estilo y la temática de algunos de sus trabajos son dificiles de clasificar dentro de las principales corrientes de la filosofía analítica. Al igual que otros de sus colegas en Harvard (en otro tiempo, C.I. Lewis, del que el propio Goodman fue discípulo, y, más recientemente, Quine, Putnam, Nozick, Rawls, etc.), más que seguir determinadas corrientes, las inaugura. 